\title{
Circulating TGF- $\beta 1$ as the potential epithelial mesenchymal transition-biomarker for diagnosis of cholangiocarcinoma
}

\author{
Phongsaran Kimawaha $^{1,2}$, Apinya Jusakul ${ }^{1,2}$, Prem Junsawang ${ }^{3}$, Watcharin Loilome ${ }^{2,4}$, Narong Khuntikeo ${ }^{2,5}$, \\ Anchalee Techasen ${ }^{1,2}$ \\ ${ }^{1}$ Faculty of Associated Medical Sciences, ${ }^{2}$ Cholangiocarcinoma Research Institute, ${ }^{3}$ Department of Statistics, Faculty of Science, ${ }^{4}$ Department of \\ Biochemistry, Faculty of Medicine, ${ }^{5}$ Department of Surgery, Faculty of Medicine, Khon Kaen University, Khon Kaen, Thailand \\ Contributions: (I) Conception and design: P Kimawaha, A Jusakul, A Techasen; (II) Administrative support: W Loilome, N Khuntikeo, A Techasen; (III) \\ Provision of study materials or patients: W Loilome, N Khuntikeo, A Techasen; (IV) Collection and assembly of data: P Kimawaha; (V) Data analysis \\ and interpretation: P Kimawaha, P Junsawang, A Techasen; (VI) Manuscript writing: All authors; (VII) Final approval of manuscript: All authors. \\ Correspondence to: Anchalee Techasen, PhD. Department of Clinical Microbiology, Faculty of Associated Medical Sciences, Khon Kaen University, \\ Khon Kaen, 40002, Thailand. Email: anchte@kku.ac.th.
}

Background: Cholangiocarcinoma (CCA) is a malignant tumor arising from bile duct epithelium. The oncogenic risk factor is infection by the liver fluke, Opisthorchis viverrini (Ov). One of key mechanism in the development of CCA is epithelial mesenchymal transition (EMT). We aimed to investigate the expression of EMT-related proteins namely, E-cadherin, TGF- $\beta 1$ and BMP-7 in CCA tissues, to determine the level of candidate EMT-related protein, and to examine whether there were significant correlations with clinicopathological data in sera of CCA patients compared with normal groups.

Methods: The expression of E-cadherin, TGF- $\beta 1$ and BMP-7 was analyzed in human CCA tissues by immunohistochemistry and altered expressions compared to clinicopathological data were analyzed to identify the potential candidate EMT-biomarker. Subsequently, the level of candidate marker was determined in sera of CCA patients compared with normal and inflammatory-related diseases groups by enzyme-linked immunosorbent assay (ELISA).

Results: Immunohistochemical analysis showed that E-cadherin was expressed at a low level whereas TGF- $\beta 1$ and BMP-7 showed high expression in CCA tissues when compared with liver from cadaveric donor. Interestingly, only high TGF- $\beta 1$ expression in CCA tissues was significantly correlated with lymph node metastasis, severe cancer stage, intrahepatic CCA type and shorter survival time of CCA patients $(\mathrm{P}<0.05)$. Consequently, TGF- $\beta 1$ was selected to determine the level in serum of CCA patients using ELISA. The results showed that serum TGF- $\beta 1$ level was elevated in CCA patients compared to the normal group. Patients with high TGF- $\beta 1$ levels were significantly correlated with metastasis status $(\mathrm{P}=0.03)$. Furthermore, receiver operating characteristic (ROC) analysis showed that serum TGF- $\beta 1$ level is effective in distinguishing CCA patients from normal at the cut-off of $38.54 \mathrm{ng} / \mathrm{mL}$ with high sensitivity $(71.1 \%)$ and specificity (68.9\%) and from inflammatory-related diseases group at the cut-off of $38.67 \mathrm{ng} / \mathrm{mL}$ with effective sensitivity $(68.0 \%)$ and specificity (71.1\%). Furthermore, TGF- $\beta 1$ could serve as a novel metastatic biomarker in CCA to diagnose the disease with $48.95 \mathrm{ng} / \mathrm{mL}$ as the cut-off along with the desired sensitivity and specificity (48.2\% and $88.9 \%$ respectively).

Conclusions: The results of this study show that TGF- $\beta 1$ could be a potential EMT-biomarker for diagnosis and prognosis of CCA.

Keywords: Cholangiocarcinoma (CCA); epithelial mesenchymal transition (EMT); E-cadherin; transforming growth factor- $\beta 1$ (TGF- $\beta 1$ ); bone morphogenetic protein-7 (BMP-7)

Submitted Oct 12, 2018. Accepted for publication Jan 04, 2019.

doi: 10.21037 /jgo.2019.01.03

View this article at: http://dx.doi.org/10.21037/jgo.2019.01.03

(c) Journal of Gastrointestinal Oncology. All rights reserved. 


\section{Introduction}

Cholangiocarcinoma (CCA) is a malignant cancer of bile duct epithelial cells arising from the biliary tract. It is a common liver cancer in Southeast Asia and it is a major public health problem in northeast Thailand (1). The major oncogenic risk factor associated with CCA development is infection by the liver fluke, Opisthorchis viverrini (Ov), that induces chronic inflammation and advanced periductal fibrosis $(2,3)$. Moreover, the essential problem related to this malignancy is an accurate and early prognosis of CCA which has proven to be very poor and difficult to diagnose until the disease becomes an advanced stage (4). Medical treatment options are especially limited, and overall survival rates in patients are low. Consequently, the identification and validation of biomarkers that could be clinically used in screening, prognosis and diagnosis of CCA are urgently required.

Epithelial mesenchymal transition (EMT), one of the key mechanisms involved in cancer development is characterized by a loss of epithelial cells and transformation to mesenchymal phenotypes with increased migratory capacity of epithelial cells. The concept that EMT involved the formation of metastatic cancer cells was based on the acquisition of mesenchymal and loss of epithelial cell adhesion molecules (5). In addition, many protein types including epithelial and mesenchymal proteins, transcription factors, contribute to EMT process. Previous studies have indicated these protein expressions in human tissues or sera can be potential biomarkers for targeting and characterization of EMT process in many diseases especially in cancers $(6,7)$.

E-cadherin, the potential epithelial marker of EMT, is an adhesion molecule normally expressed on epithelial cells (8). Some studies have suggested that loss of cell-cell adhesion contributes to the detachment of tumor cells and allows them to exceed normal barriers and migrate to distant sites. Several studies reported a difference in E-cadherin expression in breast cancer compared to normal tissue $(9,10)$. A soluble peptide fragment detected as E-cadherin is probably a degradation product of $\mathrm{E}$-cadherin generated by a $\mathrm{Ca}^{2+}$-dependent proteolytic action, and the soluble form can found in blood circulation in many diseases such as primary Sjogren's syndrome, gastric and bladder cancers (11).

Transforming growth factor- $\beta 1$ (TGF- $\beta 1$ ), is a multifunctional polypeptide with potent effects as a growth inhibitor for most epithelial cells and mesenchymal cells. Studies suggest that the TGF- $\beta 1$ signaling system plays a role in carcinogenesis and cancer progression (12). Clinically, TGF- $\beta 1$ is often elevated in the plasma of patients with malignant tumors. Several models have shown correlations between TGF- $\beta 1$ expression and increased tumorigenic and invasion (13). However, little work has been done concerning the circulation of TGF- $\beta 1$ in CCA patients.

Bone morphogenetic protein-7 (BMP-7), the member of TGF- $\beta$ superfamily is thought to have inhibitory effects on CCA development since it is able to counteract TGF$\beta$-induced CCA cell migration (14). Moreover, plasma levels of BMP-7 were significantly elevated in patients with chronic liver disease compared with healthy group (15). Nevertheless, only a few studies have measured circulating BMP-7 levels in cancer stages.

The interactions between the three EMT-related proteins have been described in many studies which have found that BMP-7 supports the epithelial phenotype by inducing the expression of Smad7 that inhibits TGF- $\beta$ signaling, and that $\mathrm{Id} 2 / 3$ inactivates the repressor E2A to permit expression of E-cadherin (16). The abnormal conversion in these EMT biomarkers can be useful for the recognition of phenotypic transitions and can be found in the circulation of normal individuals but is particularly elevated in patients with malignancies. Hence, the alteration of EMT-related proteins may be used as novel biomarkers for diagnosis of cancer patients.

Our study aimed to investigate the expression of E-cadherin, TGF- $\beta 1$ and BMP-7 in human CCA tissues and whether there were correlations in its expression with clinicopathological data of CCA patients. Subsequently, potential candidate EMT biomarkers were identified in sera of CCA patients and compared with normal and inflammatory-related diseases group. Identification of candidate EMT biomarkers may prove useful in prediction or diagnosis of CCA patients.

\section{Methods}

\section{Human CCA tissue and serum specimens}

All human specimens and the protocols in these studies were approved by the Human Ethics Committee of Khon Kaen University, based on the ethics of human specimen experimentation of the National Research Council of Thailand (HE571283 and HE531320) and informed consent was obtained from each subject before surgery. All surgical tissue samples were histopathologically ascertained. The 
paraffin-embedded CCA tissues $(\mathrm{n}=50)$ and sera of CCA patients $(n=45)$ were collected from Srinagarind hospital and kept in the biospecimen bank of Cholangiocarcinoma Research Institute (CARI), Khon Kaen University. Samples with other disease conditions related inflammation $(n=25)$ were also recruited in this study. In addition, sera of people who had normal abdominal ultrasonography $(n=45)$ were collected from Ban Wa subdistinct, Khon Kaen province.

\section{Immunohistochemistry staining of human CCA tissues}

Immunohistochemistry was performed to determine the expressions of E-cadherin, TGF- $\beta 1$ and BMP-7 in human CCA tissues. Briefly, paraffin-embedded tissues were passed through graded ethanol solutions to deparaffinized and rehydrate the sections. Antigen retrieval was performed by heating the sections in a microwave oven in $10 \mathrm{mM}$ citrate buffer $\mathrm{pH} 6.0$ for 10 minutes, while $0.3 \%$ (v/v) hydrogen peroxide was used to block endogenous peroxidase activity. Then, $10 \%$ skim milk in PBS was added to block non-specific substances in tissues. Each section was incubated with primary antibody; mouse antihuman E-cadherin antibody (1:50, 610182, BD Biosciences, USA), or mouse anti-human TGF- $\beta 1$ antibody (1:500, LS-C104537, LifeSpan BioSciences, USA), or rabbit anti-human BMP-7 antibody (1:200, AHP961, Bio$\mathrm{rad}, \mathrm{UK})$ at $4{ }^{\circ} \mathrm{C}$ overnight. After that, sections were washed in $0.1 \%$ Tween 20 in PBS and incubated with horseradish peroxidase-conjugated EnvisionTM secondary antibody (Dako, USA). The color was developed with 3,3' diaminobenzidine tetrahydrocholoride (DAB) substrate kit (Vector Laboratories, Ca), then counterstained with Mayer's haematoxylin. The sections were rehydrated with stepwise increasing concentration of ethanol and mounted with permount solution. The stained sections were examined under a light microscope. The Histoscore (H-score) was used for analysis of immunohistochemical staining, this method calculated by semi-quantitative assessment of both the intensity of staining; graded as 0 , no staining; 1 , weak; 2 , moderate; or 3 , strong and the percentage of positive cells (0-100\%). The range of possible scores was from 0 to 300 . The expression level of each section was categorized as low or high according to the median value of the $\mathrm{H}$-score (17).

\section{Candidate EMT-related proteins selection}

Candidate EMT-related proteins were selected based on statistical analysis between expression in CCA tissues and the clinicopathological data of CCA patients.

\section{Sandwich enzyme-linked immunosorbent assay (ELISA) for TGF- $\beta 1$ detection}

A sandwich ELISA was performed to determine the candidate EMT biomarker level which was found to be TGF- $\beta 1$. Quantitation of TGF- $\beta 1$ in sera of CCA patients and other disease patients were compared with normal ultrasonography group by using Quantikine ELISA Kit (R\&D systems, USA). Before the assay, the latent form of TGF- $\beta 1$ contained in patients' serum was activated to the immunoreactive form using $1 \mathrm{~N} \mathrm{HCl}$ for acid activation

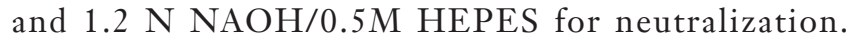
The sandwich ELISA was performed according to the manufacturer's instructions. Briefly, the plate that was coated with primary antibody specific to TGF- $\beta 1$ was added with assay diluent to each well. Standard, control, and activated samples were added to each well and incubated for 2 hours at room temperature. After washing, the polyclonal antibody specific for TGF- $\beta 1$ conjugated to horseradish peroxidase was added, after 2 hours' incubation time. Then, $100 \mu \mathrm{L}$ of substrate solution was added to each well for 30 minutes at room temperature and protect from light. The reaction was stopped with hydrochloric acid and the plates were read on an ELISA reader using Magellan at the optical density (OD) at $450 \mathrm{~nm}$. The results were calculated by reference to the standard curve.

\section{Statistical analysis}

Statistical analyses were performed using SPSS V.23.0 (IBM Corporation, USA). Data were represented as mean \pm SD. The association of EMT-related protein expressions in tissues and the level in sera were calculated with clinicopathological parameters of CCA patients by $X^{2}$ test. The log-rank test was used to compare survival distributions and Kaplan-Meier method was plotted for survival analysis. The diagnostic performance of candidate EMT-biomarker was evaluated using receiver operating characteristic (ROC) curve analysis, area under the ROC curve (AUC) with 95\% CI, and Youden index were calculated. Analysis of variance (ANOVA) was used to compare the mean levels of candidate biomarker and clinicopathological parameters. Odd ratios $(\mathrm{OR})$ were analyzed to predict risk score. Univariate and multivariate analysis including linear and multiple 

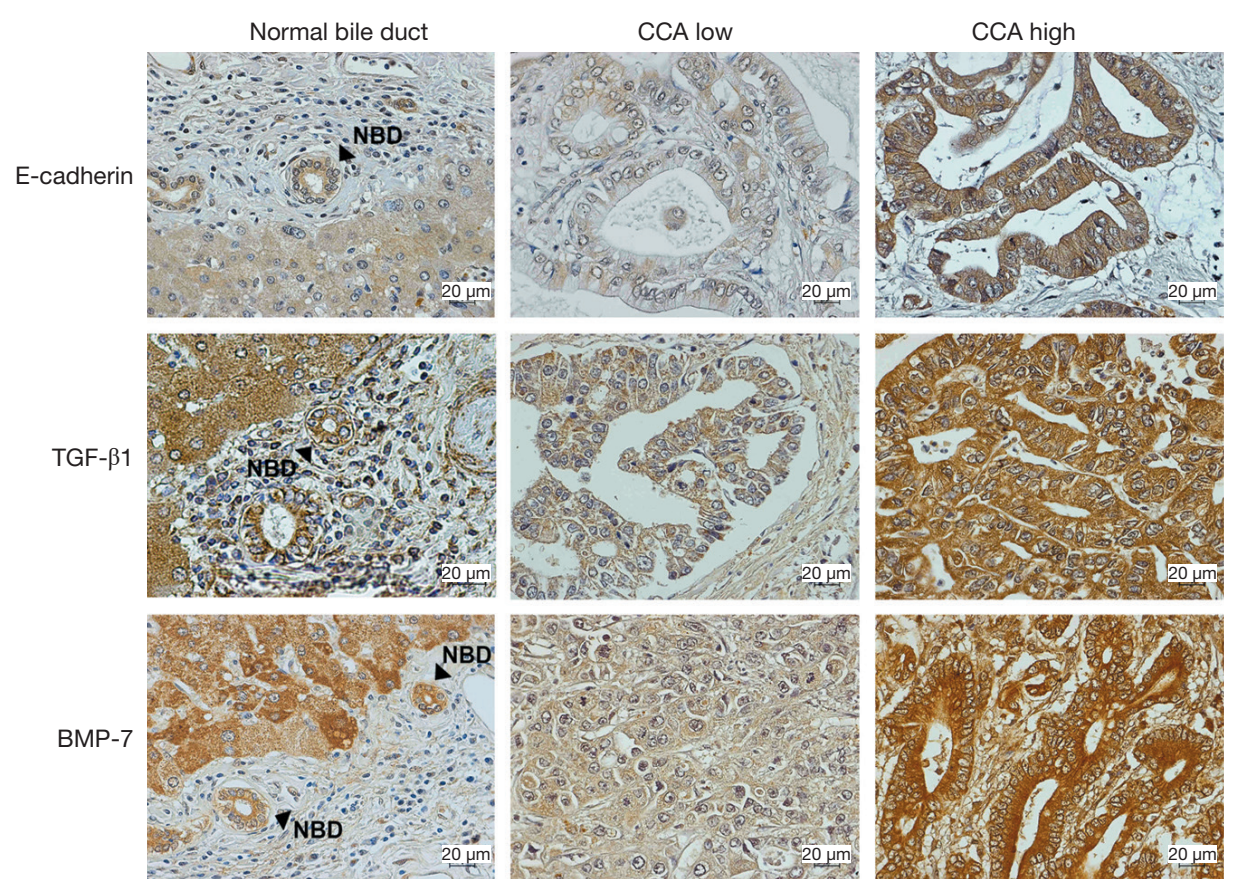

Figure 1 Immunohistochemical staining for E-cadherin, TGF- $\beta 1$, and BMP-7 in human CCA tissues were classified as low and high levels according to $\mathrm{H}$-score. An original magnification is $\times 40$ for all figures. CCA low refers to low expression of E-cadherin, TGF- $\beta 1$ and BMP7 in CCA tissue; CCA high refers to high expression of E-cadherin, TGF- $\beta 1$ and BMP-7 in CCA tissue. TGF- $\beta 1$, transforming growth factor- $\beta 1$; BMP-7, bone morphogenetic protein-7; CCA, cholangiocarcinoma.

regression was also calculated. The Cox proportional hazards models were used to estimate hazard ratios and $95 \%$ confidence intervals (95\% CI) with adjustment for other variables. Values of $\mathrm{P} \leq 0.05$ were considered statistically significant.

\section{Results}

Immunobistochemical analysis of E-cadherin, TGF- $\beta 1$, and BMP-7 in buman CCA tissues

The immunoreactivity of E-cadherin, TGF- $\beta 1$, and BMP7 was predominantly found in cytoplasmic staining of all CCA tissues. The expression of E-cadherin was higher in normal bile ducts when compared with tumor cells. The immunohistochemical staining of E-cadherin showed the low expression in 23/50 cases (46\%) and high expression in $27 / 50$ cases (54\%). Contrastingly, the expression of TGF- $\beta 1$ and BMP-7 showed weakly stained in normal bile ducts area whereas strongly stained was observed in tumor cells. Low TGF- $\beta 1$ expression was detected in $16 / 50$ cases (32\%) and high TGF- $\beta 1$ was majorly found in $34 / 50$ cases $(68 \%)$.
In addition, low BMP-7 was observed in 24/50 (48\%) and high BMP-7 was observed in 26/50 (52\%) of CCA tissues (Figure 1).

\section{E-cadherin, TGF- $\beta 1$, and BMP-7 expressions in correlation to clinicopathological data}

The CCA tissues were obtained from 50 patients, 19 females (38\%) and 31 males (62\%). The mean age of patients was 58.28 years (range, $38-82$ years). As shown in Table 1, high TGF- $\beta 1$ expression was significantly correlated with lymph node metastasis $(\mathrm{P}=0.002)$, severe TNM stage (stage IV) $(\mathrm{P}=0.021)$, and associated with intrahepatic CCA type $(\mathrm{P}=0.011)$. On the other hand, there was no significant correlation of E-cadherin and BMP-7 expression with any clinicopathological parameters.

\section{The altered expressions of E-cadherin, TGF- $\beta 1$, and BMP-7 in CCA tissues with survival rate of patients}

Figure 2 shows the overall and disease-free survival (DFS) analysis by Kaplan-Meier method with a log rank 
Table 1 Correlation between E-cadherin, TGF- $\beta 1$, and BMP-7 expressions and clinicopathological data in CCA patients

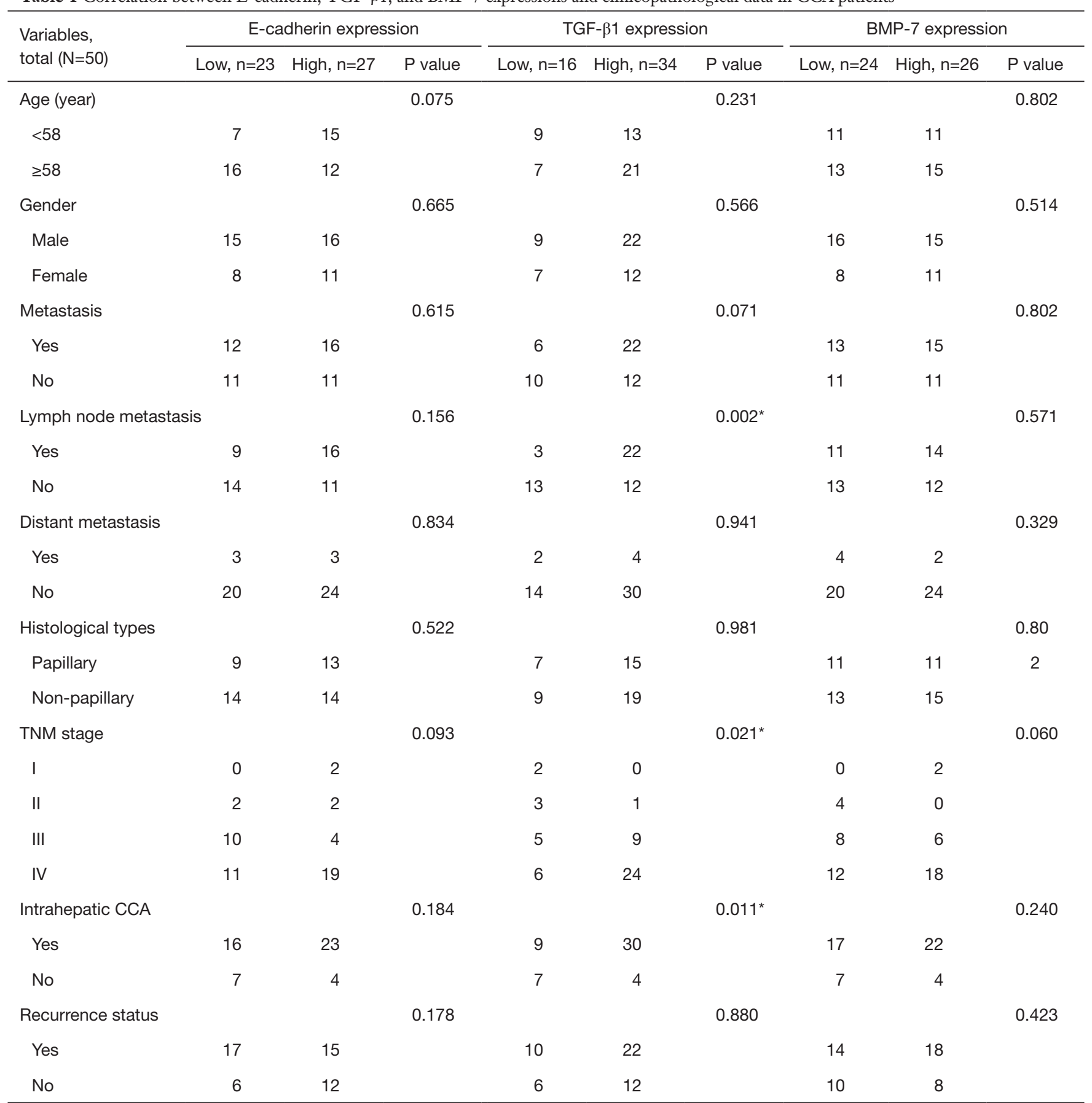

The symbol $\left(^{*}\right)$ indicates $P$ value $\leq 0.05$ that was considered statistically significant. TGF- $\beta 1$, transforming growth factor- $\beta 1$; BMP-7, bone morphogenetic protein-7; CCA, cholangiocarcinoma.

test revealed that there was no significantly correlated between E-cadherin and BMP-7 expressions with overall survival time of CCA patients $(\mathrm{P}=0.125$ and $\mathrm{P}=0.857$, respectively). Interestingly, CCA patients who had high expression of TGF- $\beta 1$ exhibited significant correlation with shorter survival and poorer prognosis than those with low expression $(\mathrm{P}=0.007)$ as shown in Figure $2 B$. The mean overall survival times between low and high expression of 

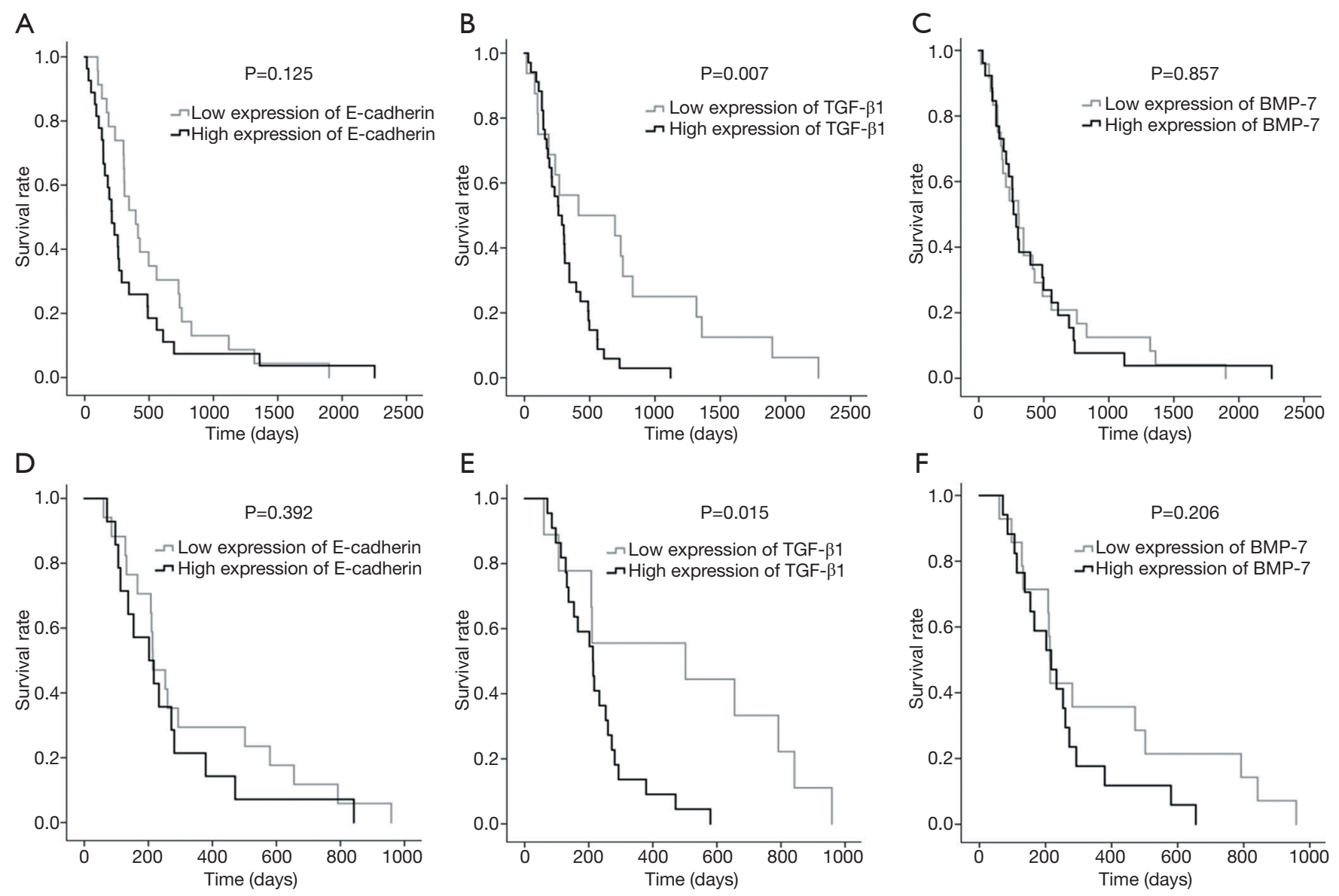

Figure 2 OS analysis according to the Kaplan-Meier method with a log rank test calculated for E-cadherin (A), TGF- $\beta 1$ (B), and BMP-7 (C) with survival rate in CCA patients. DFS analysis was plotted to evaluate the recurrence status in accordance with the expression of E-cadherin (D), TGF- $\beta 1$ (E), and BMP-7 (F). P $\leq 0.05$ was considered statistically significant. TGF- $\beta 1$, transforming growth factor- $\beta 1$; BMP-7, bone morphogenetic protein-7; CCA, cholangiocarcinoma; DFS, disease-free survival.

TGF- $\beta 1$ were 23.4 and 10.5 months, respectively. The DFS analysis was calculated to determine the recurrence status of CCA patients after surgery. The DFS curve showed patients who had increased expression of TGF- $\beta 1$ were significantly associated with recurrence status, short-time survival, and poor prognosis than those with decreased expression $(\mathrm{P}=0.015)$ as shown in Figure $2 E$. The mean DFS times between low and high expression of TGF- $\beta 1$ were 16.0 and 7.5 months, respectively.

\section{TGF- $\beta 1$ is selected to be the candidate protein for measuring the level in sera of CCA patients}

From the previous results, only TGF- $\beta 1$ expression in CCA tissue was significantly correlated with many parameters of CCA patients including lymph node metastasis, severe cancer stage, and intrahepatic CCA type $(\mathrm{P}<0.05)$. The overall and DFS analysis illustrated that elevated TGF- $\beta 1$ expression was associated with short-survival time and contributed to poor prognosis in CCA patients $(\mathrm{P}<0.05)$. Consequently, TGF- $\beta 1$ was selected to be the proper potential EMT-biomarker for further analysis in blood circulation of CCA patients.

\section{Measurement of TGF-p1 level in serum of CCA patients}

Serum levels of TGF- $\beta 1$ in all experimental groups are presented in Figure 3 as column bar graph (mean \pm SD). The results revealed that CCA patients had significantly higher serum TGF- $\beta 1$ levels $(42 \pm 15.90 \mathrm{ng} / \mathrm{mL})$ than those 


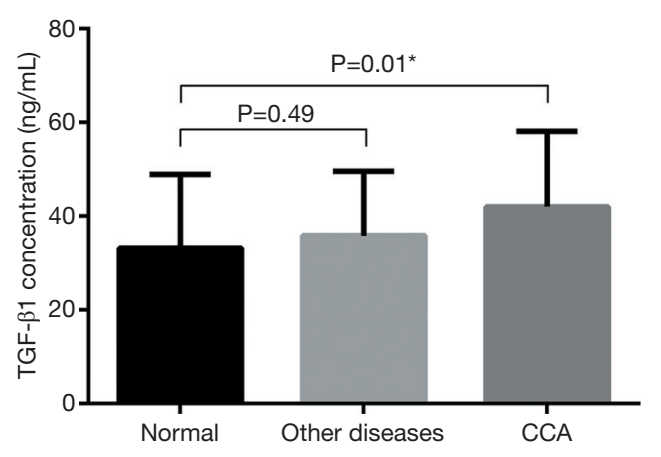

Figure 3 Serum levels of TGF- $\beta 1$ in normal group, other diseases group, and CCA patients. Column bars represent mean \pm SD. The symbol $\left(^{*}\right)$ indicates that $\mathrm{P} \leq 0.05$ was considered statistically significant when compared with normal control group. TGF- $\beta 1$, transforming growth factor- $\beta 1$; CCA, cholangiocarcinoma.

in the normal control group $(33.18 \pm 15.50 \mathrm{ng} / \mathrm{mL})(\mathrm{P}=0.01)$. No significant differences were observed between TGF- $\beta 1$ level $(35.76 \pm 13.52 \mathrm{ng} / \mathrm{mL})$ in other diseases group as compared to normal control group and CCA patients.

\section{Correlation between TGF- $\beta 1$ level in serum with clinicopathological data and laboratory results}

To assess the association between TGF- $\beta 1$ levels in serum from ELISA and clinicopathological variables and laboratory results of CCA patients the sera from 45 cases of CCA were included in this study. Elevated TGF- $\beta 1$ levels in sera were found to be significantly correlated with metastasis status $(\mathrm{P}=0.030)$. In addition, the positive correlation between TGF- $\beta 1$ level, platelet smear $(\mathrm{P}=0.014)$ and CA19-9 level $(\mathrm{P}=0.033)$ was observed (Table 2$)$. However, there was no significant correlation of TGF- $\beta 1$ level with age, sex, histological types, survival days, recurrence, TNM stages, lymph node and distant metastatic stages.

\section{Predictive values of serum TGF- $\beta 1$ level for CCA diagnosis}

To evaluate the performance of TGF- $\beta 1$ as a potential EMT biomarker for CCA, the receiver-operator characteristic (ROC) curve and area under curve (AUC) were analyzed. The concentration of TGF- $\beta 1$ based on the optimal cut-off derived from ROC analysis and Youden index calculation is presented in Table 3. ROC curve analysis showed that the TGF- $\beta 1$ level could be used to differentiate between the
Table 2 Clinicopathological data, laboratory results and the mean value of serum levels of TGF- $\beta 1$ in patients with CCA according to variables as listed

\begin{tabular}{|c|c|c|c|}
\hline Variables & No. of patients & TGF- $\beta 1$ (ng/mL) & $P$ value \\
\hline Age (year) & & & 0.729 \\
\hline$<59$ & 23 & $41.17 \pm 16.66$ & \\
\hline$\geq 59$ & 22 & $42.86 \pm 15.80$ & \\
\hline Sex & & & 0.774 \\
\hline Male & 29 & $42.51 \pm 16.44$ & \\
\hline Female & 16 & $41.05 \pm 15.90$ & \\
\hline Histological types & & & 0.470 \\
\hline Papillary & 20 & $43.96 \pm 15.85$ & \\
\hline Non-papillary & 25 & $40.42 \pm 16.41$ & \\
\hline Survival days & & & 0.178 \\
\hline$<371$ & 27 & $44.64 \pm 16.24$ & \\
\hline$\geq 371$ & 18 & $38.02 \pm 15.42$ & \\
\hline Recurrence & & & 0.583 \\
\hline Yes & 18 & $43.63 \pm 19.98$ & \\
\hline No & 27 & $40.90 \pm 13.18$ & \\
\hline TNM stages & & & 0.084 \\
\hline I & 2 & $37.72 \pm 7.92$ & \\
\hline II & 4 & $29.09 \pm 13.53$ & \\
\hline III & 14 & $49.92 \pm 13.04$ & \\
\hline IV & 25 & $39.98 \pm 16.93$ & \\
\hline Metastasis & & & $0.030^{*}$ \\
\hline Yes & 27 & $46.19 \pm 14.40$ & \\
\hline No & 18 & $35.10 \pm 16.81$ & \\
\hline Lymph node metas & tasis & & 0.073 \\
\hline Yes & 24 & $46.01 \pm 15.14$ & \\
\hline No & 21 & $37.41 \pm 16.25$ & \\
\hline Distant metastasis & & & 0.970 \\
\hline Yes & 7 & $41.78 \pm 10.39$ & \\
\hline No & 38 & $42.03 \pm 17.03$ & \\
\hline \multicolumn{4}{|c|}{ Complete blood count } \\
\hline $\mathrm{Hb}(\mathrm{g} / \mathrm{dL})$ & & & 0.817 \\
\hline$<12$ & 21 & $41.39 \pm 13.56$ & \\
\hline$\geq 12$ & 24 & $42.52 \pm 18.29$ & \\
\hline
\end{tabular}

Table 2 (continued) 
Table 2 (continued)

\begin{tabular}{|c|c|c|c|}
\hline Variables & No. of patients & TGF- $\beta 1$ (ng/mL) & $P$ value \\
\hline Hct (\%) & & & 0.860 \\
\hline$<36$ & 20 & $41.51 \pm 13.75$ & \\
\hline$\geq 36$ & 25 & $42.38 \pm 18.00$ & \\
\hline WBC $\left(10^{3} / \mu \mathrm{L}\right)$ & & & 0.722 \\
\hline$<10.6$ & 26 & $42.74 \pm 15.92$ & \\
\hline$\geq 10.6$ & 19 & $40.98 \pm 16.69$ & \\
\hline Platelet smear & & & $0.014^{*}$ \\
\hline Decrease & 3 & $43.96 \pm 20.03$ & \\
\hline Adequate & 36 & $38.98 \pm 15.07$ & \\
\hline Increase & 6 & $59.11 \pm 10.31$ & \\
\hline Platelet count & $3 / \mu \mathrm{L})$ & & 0.136 \\
\hline$<383$ & 35 & $40.08 \pm 15.75$ & \\
\hline$\geq 383$ & 10 & $48.70 \pm 16.21$ & \\
\hline \multicolumn{4}{|l|}{ Tumor markers } \\
\hline CA19-9 (U/mL) & & & $0.033^{*}$ \\
\hline$<37$ & 10 & $36.62 \pm 11.01$ & \\
\hline$\geq 37$ & 22 & $46.68 \pm 12.13$ & \\
\hline CEA (ng/mL) & & & 0.459 \\
\hline$<2.5$ & 7 & $40.73 \pm 12.41$ & \\
\hline$\geq 2.5$ & 25 & $44.81 \pm 12.80$ & \\
\hline AFP (IU/mL) & & & 0.131 \\
\hline$<10$ & 24 & $45.76 \pm 12.40$ & \\
\hline$\geq 10$ & 2 & $31.40 \pm 14.44$ & \\
\hline
\end{tabular}

Data represent mean \pm standard deviation (SD). The symbol $\left.{ }^{*}\right)$ indicates $\mathrm{P}$ value $\leq 0.05$ that was considered statistically significant. $\mathrm{Hb}$, hemoglobin; Hct, hematocrit; WBC, white blood cell count; CA19-9, carbohydrate antigen 19-9; CEA, carcinoembryonic antigen; AFP, alpha-fetoprotein; TGF- $\beta 1$, transforming growth factor- $\beta 1$; CCA, cholangiocarcinoma. following groups; normal control and CCA patient with cut-off was $38.54 \mathrm{ng} / \mathrm{mL}(\mathrm{P}=0.006$, AUC $=0.6677$, Youden index $=139$ ), and CCA patient and other diseases group with cut-off was $38.67 \mathrm{ng} / \mathrm{mL}(\mathrm{P}=0.046$, AUC $=0.6444$, Youden index $=138.11$ ). Other ROC curves of comparison groups were shown in Figure 4, serum TGF- $\beta 1$ level could not be used to distinguish between normal and other diseases group according to insignificantly statistical value.

\section{Predictive risk of TGF- $\beta 1$ level for other diseases and $C C A$ patients}

To determine whether increasing levels of TGF- $\beta 1$ could be used to predict for CCA, calculation of crude and adjusted odds ratio (OR) was performed as shown in Table 4. Interestingly, high TGF- $\beta 1$ levels were a significant predictor to distinguish the normal control group from the CCA group $(\mathrm{OR}$ crude $=5.45, \mathrm{OR}$ adjusted $=4.74 ; \mathrm{P}<0.001$, 0.001 respectively) and other diseases from the CCA group $(\mathrm{OR}$ crude $=5.23, \mathrm{OR}$ adjusted $=5.01 ; \mathrm{P}=0.002,0.004$ respectively).

\section{TGF-ß1 could serve as a novel EMT-biomarker for metastasis in CCA}

CCA patients made up of 18 non-metastasis cases and 27 metastasis status cases were obtained and results showed that serum TGF- $\beta 1$ levels were significantly different between non-metastatic and metastatic CCA patients $(\mathrm{P}=0.030)$ as shown in Figure $5 \mathrm{~A}$. Moreover, ROC analysis showed that the TGF- $\beta 1$ could be used to differentiate metastasis from non-metastasis with a cutoff of $48.95 \mathrm{ng} / \mathrm{mL}$ which resulted in $48.2 \%$ for sensitivity and $88.9 \%$ for specificity $(\mathrm{P}=0.024$, AUC $=0.701$, Youden index $=136.1$ ) (Figure 5B). Furthermore, at cut-off of $48.95 \mathrm{ng} / \mathrm{mL}$, the TGF- $\beta 1$ level was a significant predictor

Table 3 Predictive values of serum TGF- $\beta 1$ levels for diagnosis CCA, based on the optimal cut-off derived from ROC analysis and Youden index calculation

\begin{tabular}{|c|c|c|c|c|c|c|c|}
\hline Group comparisons & AUC $(95 \% \mathrm{Cl})$ & $\begin{array}{l}\text { Cut-off } \\
\text { (ng/mL) }\end{array}$ & $\begin{array}{l}\text { Youden } \\
\text { index }\end{array}$ & $\begin{array}{c}\text { Sensitivity } \\
(\%)\end{array}$ & $\begin{array}{l}\text { Specificity } \\
(\%)\end{array}$ & LR & $P$ value \\
\hline Normal vs. CCA & $0.668(0.553-0.782)$ & 38.54 & 139.00 & 71.1 & 68.9 & 2.286 & $0.006^{*}$ \\
\hline CCA vs. other diseases & $0.644(0.508-0.781)$ & 38.67 & 138.11 & 68.0 & 71.1 & 2.354 & $0.046^{*}$ \\
\hline
\end{tabular}

The symbol $\left(^{*}\right)$ indicates $P$ value $\leq 0.05$ that was considered statistically significant. TGF- $\beta 1$, transforming growth factor- $\beta 1$; CCA, cholangiocarcinoma; AUC, area under the ROC curve; LR, likelihood ratio. 

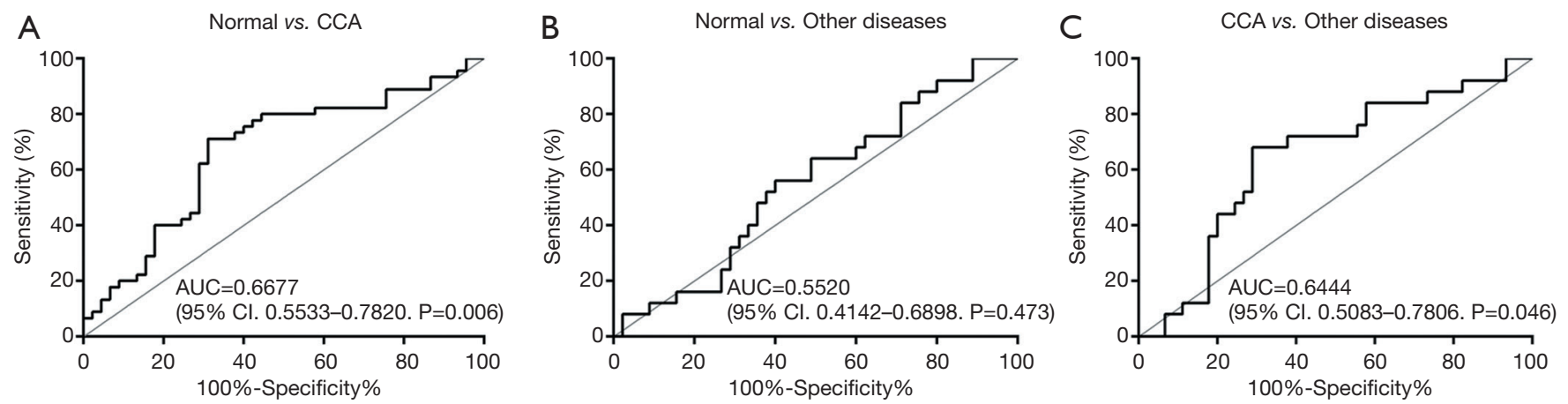

Figure 4 ROC curve of serum TGF- $\beta 1$ as a potential EMT biomarker for prediction of CCA in comparison groups (A,B,C). AUC and statistic comparison are indicated. $\mathrm{P} \leq 0.05$ was considered statistically significant. ROC, receiver operating characteristic; TGF- $\beta 1$, transforming growth factor- $\beta 1$; EMT, epithelial mesenchymal transition; CCA, cholangiocarcinoma; AUC, area under the ROC curve.

Table 4 Predictive risk of CCA and other diseases relative to normal control group by using serum levels of TGF- $\beta 1$

\begin{tabular}{lcccc}
\hline \multirow{2}{*}{ Comparative diagnosis } & \multicolumn{2}{c}{ Crude } & \multicolumn{2}{c}{ Adjusted } \\
\cline { 2 - 3 } Normal vs. CCA: TGF- $\beta 1>38.54$ vs. $\leq 38.54 \mathrm{ng} / \mathrm{mL}$ & OR $(95 \% \mathrm{Cl})$ & $\mathrm{P}$ value & $\mathrm{OR}^{*}(95 \% \mathrm{Cl})$ & $\mathrm{P}$ value \\
Normal vs. other diseases: TGF- $\beta 1>35.37$ vs. $\leq 35.37 \mathrm{ng} / \mathrm{mL}$ & $1.91(0.71-5.14)$ & 0.200 & $1.36(0.40-4.29)$ & 0.650 \\
CCA vs. other diseases: TGF- $\beta 1>38.67$ vs. $\leq 38.67 \mathrm{ng} / \mathrm{mL}$ & $5.23(1.81-15.98)$ & 0.002 & $5.01(1.70-14.78)$ & 0.004 \\
\hline
\end{tabular}

*, odds ratio adjusted for age and sex statistical analysis. TGF- $\beta 1$, transforming growth factor- $\beta 1$; CCA, cholangiocarcinoma; OR, odds ratio; $\mathrm{Cl}$, confidence interval.

to determine the metastatic status in CCA patients $(\mathrm{OR}$ crude $=7.43, \mathrm{OR}$ adjusted $=11.29 ; \mathrm{P}=0.017,0.012$ respectively) (Table 5).

\section{A combination of TGF-ß1, alkaline phosphatase (ALP), and platelet count levels to improve the diagnostic efficacy for $C C A$}

Based on ROC analysis revealed that not only TGF- $\beta 1$ but also ALP and platelet count can effectively distinguish CCA patients from normal. Moreover, only TGF- $\beta 1$ could be distinguish CCA from other diseases $(\mathrm{P}=0.046)$ (Figure 6). To improve the diagnostic efficacy for CCA, those markers were combined and analyzed together. At cut-off values for TGF- $\beta 1(38.54 \mathrm{ng} / \mathrm{mL})$ and ALP (98 U/L) were detected in $43 / 45$ CCA patients with $95.6 \%$ sensitivity. At cut-off values for TGF- $\beta 1$ and platelet count $\left(276.510^{3} / \mu \mathrm{L}\right)$ were detected in $39 / 45$ patients with $86.7 \%$ sensitivity. The combination of all three markers was detected in $43 / 45$ patients with 95.6\% sensitivity (Figure 7).

\section{Analysis the diagnostic performance of TGF- $\beta 1$ and ALP as a combination biomarker for $C C A$}

A combination of serum TGF- $\beta 1$ and ALP level had the highest sensitivity rate for CCA diagnosis (Figure 7). Hence, diagnostic testing was performed to confirm that both biomarkers correctly identify patients with or without CCA. Sensitivity and specificity values, positive predictive (PPV) and negative predictive (NPV) values, accuracy and likelihood ratio (LR) were calculated. From Table 6 , the $2 \times 2$ table was used to calculate variables of the diagnostic test from TGF- $\beta 1$ and ALP test outcome as follows; sensitivity was $95.6 \%$ (43/45), specificity was $68.9 \%$ (31/45), PPV was $75.4 \%$ (43/57), NPV was $93.9 \%$ (31/33), accuracy was $82.2 \%(74 / 90)$, and LR was $3.1(43 / 14)$. We found that a combination of serum TGF- $\beta 1$ and ALP had the ability to precisely diagnose those patients with CCA $(95.6 \%$ sensitivity) or without CCA (68.9\% specificity). Moreover, $\mathrm{PPV}$ and NPV that was used to evaluate the effectiveness of this biomarker combination in CCA diagnosis showed that $75.4 \%$ of patients with positive results of TGF- $\beta 1$ and 

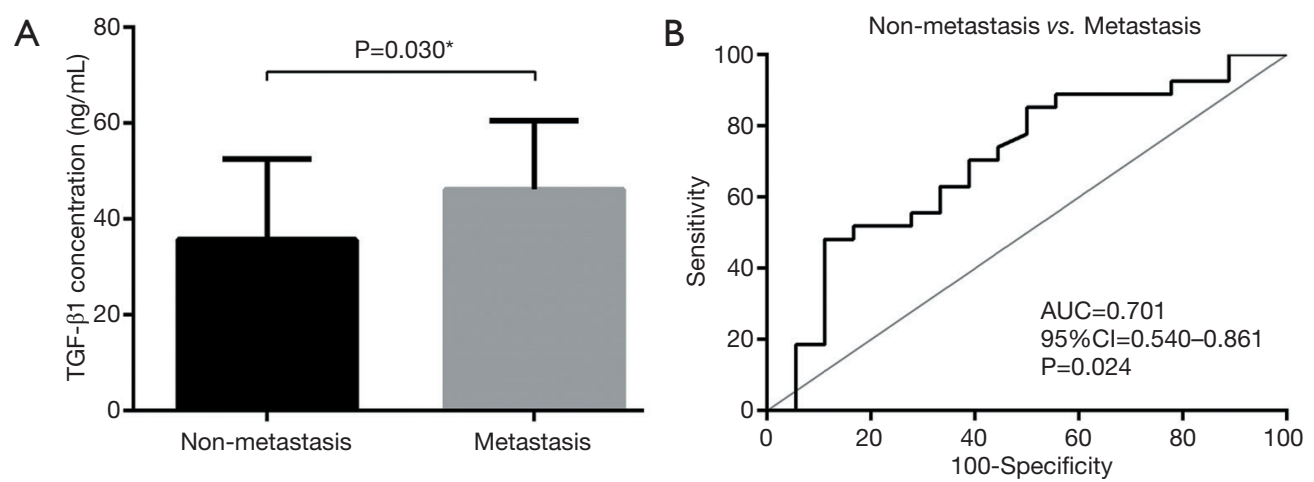

Figure 5 (A) Serum levels of TGF- $\beta 1$ in non-metastasis and metastasis in CCA patients. Column bars represent mean \pm SD. (B) The ROC curve of serum TGF- $\beta 1$ for distinguishes metastasis from non-metastasis in CCA patients. AUC and statistic comparison are indicated. $\mathrm{P} \leq 0.05$ was considered statistically significant. ROC, receiver operating characteristic; TGF- $\beta 1$, transforming growth factor- $\beta 1$; CCA, cholangiocarcinoma; AUC, area under the ROC curve.

Table 5 Predictive risk of metastatic status in CCA patients by using serum levels of TGF- $\beta 1$

\begin{tabular}{|c|c|c|c|c|}
\hline Comparative diagnosis & \multicolumn{2}{|l|}{ Crude } & \multicolumn{2}{|c|}{ Adjusted } \\
\hline $\begin{array}{l}\text { Non-metastasis vs. metastasis: TGF- } \beta 1>48.95 \text { vs. } \\
\leq 48.95 \mathrm{ng} / \mathrm{mL}\end{array}$ & $7.43(1.42-38.78)$ & 0.017 & $11.29(1.71-74.70)$ & 0.012 \\
\hline
\end{tabular}

*, odds ratio adjusted for age and sex statistical analysis. TGF- $\beta 1$, transforming growth factor- $\beta 1$; CCA, cholangiocarcinoma; OR, odds ratio; $\mathrm{Cl}$, confidence interval.
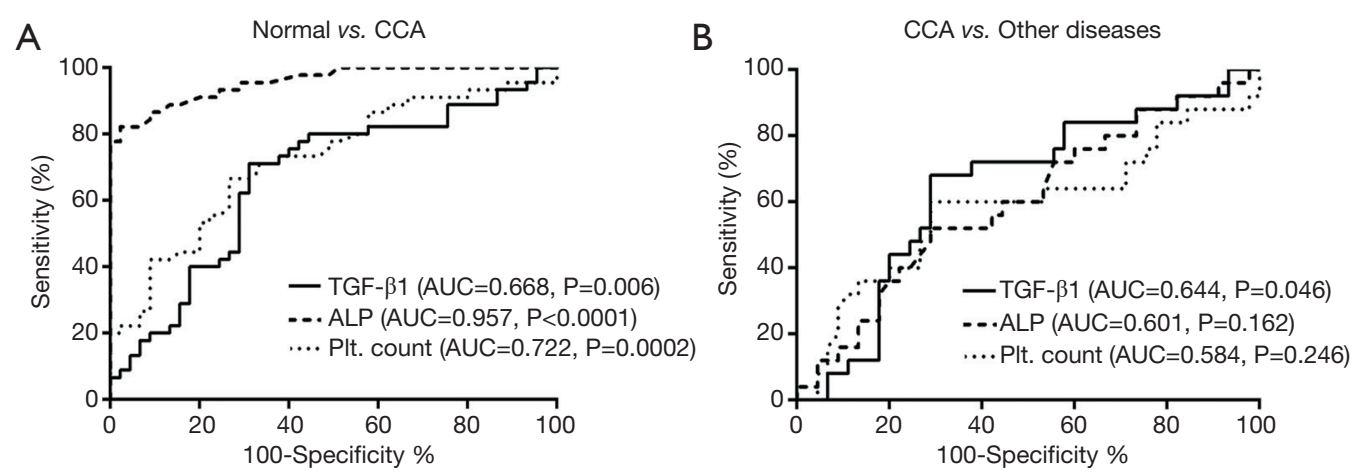

Figure 6 Comparisons in ROC curve analysis of a combination of serum TGF- $\beta 1$, alkaline phosphatase (ALP), and platelet count in CCA patients compared with normal and other diseases group (A,B). AUC and statistic comparison are indicated. $\mathrm{P} \leq 0.05$ was considered statistically significant. ROC, receiver operating characteristic; TGF- $\beta 1$, transforming growth factor- $\beta 1$; CCA, cholangiocarcinoma; AUC, area under the ROC curve.

ALP actually had this disease and that $93.9 \%$ of patients with negative results were actually disease free. Serum TGF- $\beta 1$ and ALP showed a high accuracy $(82.2 \%)$ and that this biomarker combination could correctly differentiate
CCA patients and normal cases. To assess the value of performing a diagnostic test, LR for positive test result was 3.1 confirmed that serum TGF- $\beta 1$ and ALP level associated with CCA. 


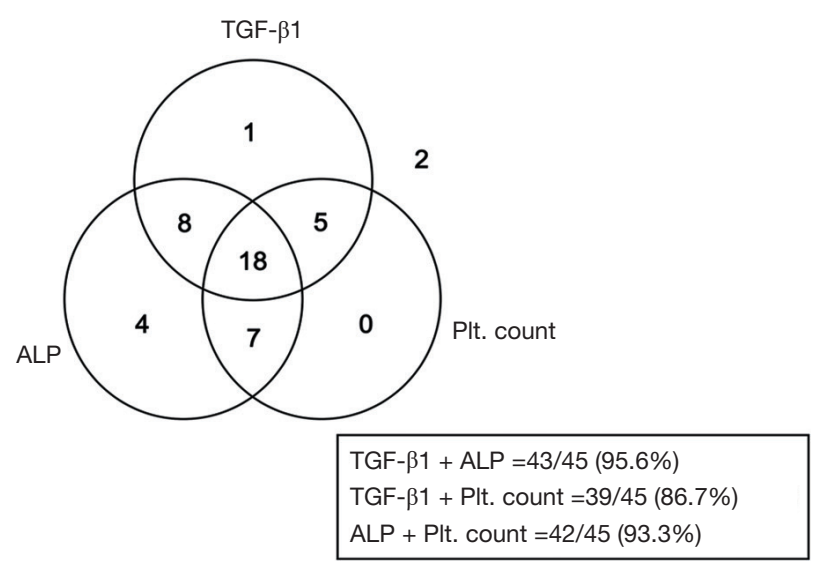

Figure 7 Comparison of CCA positive rates obtained when combining two biomarkers. Two CCA patients were negative for all three biomarkers. The CCA detection rates of the combination of TGF- $\beta 1$ and ALP, TGF- $\beta 1$ and platelet count, and ALP and platelet count were $95.6 \%$ (43/45), 86.7\% (39/45) and $93.3 \%$ (42/45), respectively. TGF- $\beta 1$, transforming growth factor- $\beta 1$; CCA, cholangiocarcinoma; ALP, alkaline phosphatase.

\section{The association of clinicopathological variables potentially associated with TGF- $\beta 1$ level}

A linear and multiple regression analysis on clinicopathological variables were performed to determine the association with TGF- $\beta 1$ levels and other factors as shown in Table 7 . This analysis found that TGF- $\beta 1$ levels were associated with age $\left(\mathrm{R}^{2}=0.040 ; \mathrm{P}=0.031\right)$, WBC $\left(\mathrm{R}^{2}=0.042 ; \mathrm{P}=0.028\right)$, platelet count $\left(\mathrm{R}^{2}=0.094 ; \mathrm{P}=0.001\right)$, and increased platelet smear $\left(\mathrm{R}^{2}=0.138 ; \mathrm{P}<0.0001\right)$. However, only an age (coefficients $=-0.175 ; \mathrm{P}=0.045)$ and increased platelet smear (coefficients $=0.290 ; \mathrm{P}=0.006$ ) were found to be strongly correlated with elevated TGF- $\beta 1$ concentrations by multiple regression analysis. The $\mathrm{R}^{2}$ and $\mathrm{P}$ value of the overall multiple regression model were 0.19 and $<0.001$ respectively.

\section{Discussion}

In the present study, we found that three EMT-related proteins had different expression levels in tissues of

Table 6 The diagnostic power of the combination biomarkers TGF- $\beta 1$ and alkaline phosphatase (ALP) in differentiating CCA from normal individuals

\begin{tabular}{|c|c|c|c|c|c|c|c|c|c|}
\hline Cut-off value & Test result & \multicolumn{2}{|c|}{ Actual status } & Sensitivity (\%) & Specificity (\%) & $\begin{array}{l}\text { PPV } \\
(\%)\end{array}$ & $\begin{array}{l}\text { NPV } \\
(\%)\end{array}$ & $\begin{array}{l}\text { Accuracy } \\
(\%)\end{array}$ & LR \\
\hline \multirow{2}{*}{$\begin{array}{l}\text { TGF- } \beta 1+\text { ALP }(38.54 \text { ng/mL, } \\
98 \text { U/L) }\end{array}$} & + & 43 & 14 & 95.6 & 68.9 & 75.4 & 93.9 & 82.2 & 3.1 \\
\hline & - & 2 & 31 & & & & & & \\
\hline
\end{tabular}

TGF- $\beta 1$, transforming growth factor- $\beta 1$; CCA, cholangiocarcinoma; PPV, positive predictive value; NPV, negative predictive value; LR, Likelihood ratio.

Table 7 Univariate and multivariate regression analyses of clinicopathologic variables potentially associated with TGF- $\beta 1$ levels

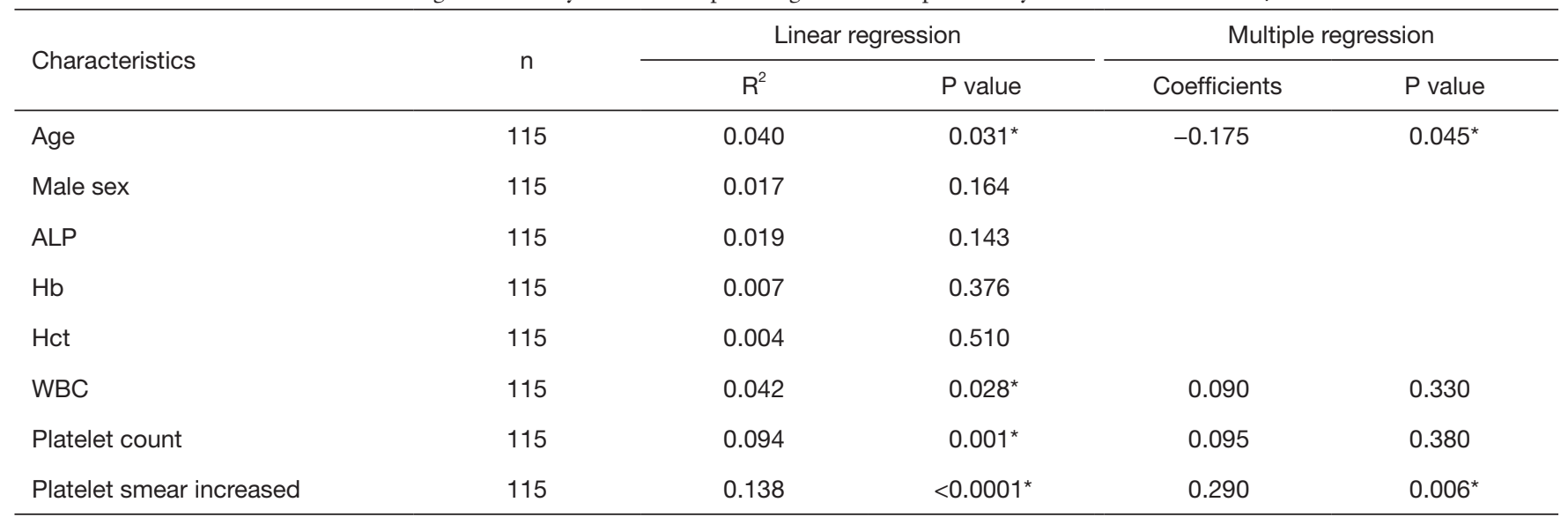

The symbol $\left(^{*}\right)$ indicates that $P$ value $\leq 0.05$ was considered statistically significant. Variables found insignificant by linear regression were not included in the multiple regression model. TGF- $\beta 1$, transforming growth factor- $\beta 1$; ALP, alkaline phosphatase. 
CCA patients. For E-cadherin, a calcium-dependent transmembrane glycoprotein, plays a critical parts in stabilizing the tight junctions and structures of different epithelia (5). Many studies have found that a low or aberrant expression of E-cadherin in various tumors showed the contrasting in percentage between $20 \%$ and $90 \%$ (18). In our study, we detected low immunoreactions of E-cadherin in $23 / 50$ CCA patients (46\%), which was equal to that reported by Zhou et al. (46\%) in gastric carcinoma (19), and similar to Ashida et al. (45\%) (20), and Techasen et al. $(52 \%)$ in CCA (21). In our study BMP-7, a novel TGF- $\beta$ inhibitor, was highly expressed in 26/50 CCA patients (52\%) which was similarly to the BMP-7 immunohistochemical expression reported by Aoki et al. which showed 55\% in gastric cancer (22). Interestingly, CCA patients that express high level of TGF- $\beta 1$ in tumor cells have greater possibilities of lymph node metastasis, severe tumor stage and concern in intrahepatic CCA than those with low level of TGF- $\beta 1$ expression. Furthermore, cumulative OS and DFS analysis showed that CCA patients in our study with high expression of TGF- $\beta 1$ had a significantly poorer prognosis, shorter survival time, and recurrence status $(\mathrm{P}=0.007, \mathrm{P}=0.015$ respectively). These data further support that a high level of TGF- $\beta 1$ is associated with CCA progression and metastasis. There are the studies reported that expression of TGF- $\beta 1$ was associated with invasion and metastasis in intrahepatic CCA (13) and oral squamous cell carcinoma (23).

TGF- $\beta$ signaling pathway plays a major role in EMT process to activate the SMAD dependent and non-dependent pathways and consequently plays a role in tumor metastasis because many studies have confirmed that EMT has a crucial biological pathway that enhances metastasis in various types of cancer $(24,25)$. In CCA, TGF- $\beta 1$ is upregulated and involved in cadherin switching that promotes cancer progression (26). In addition, the mechanism of TGF- $\beta 1$ can induced mesenchymal phenotypes in CCA cell lines, and promoted the activity of invasive potential both in vitro and in vivo, which was accompanied by the induction of Snail transcription factor (27).

We then determined the serum level of TGF- $\beta 1$ in CCA patients compared to normal control and other diseases groups. Our results showed a significant elevated concentration of TGF- $\beta 1$ when compared to healthy individuals $(\mathrm{P}=0.01)$. The highest serum levels of TGF- $\beta 1$ in cancer are consistent with those of Saito et al. (28) and Li et al. (29) who found higher level of TGF- $\beta 1$ in sera of patients with gastric carcinoma. Furthermore, our study also showed that serum TGF- $\beta 1$ levels in CCA are related with metastasis status likewise immunohistochemical result. Furthermore, TGF- $\beta 1$ could serve as a novel metastatic biomarker in CCA because it can distinguish metastasis from non-metastasis CCA patients with a cut-off of $48.95 \mathrm{ng} / \mathrm{mL}$. The metastatic function of TGF- $\beta 1$ had been proved in CCA cell line that TGF- $\beta$ potentially induces CCA cell migration, one of the metastatic processes possibly via activation of Twist, $\mathrm{N}$-cadherin and vimentin expression in EMT process (14). We found that serum levels of TGF- $\beta 1$ rise with increasing platelet smear, and serum levels of CA19-9. Hence, increasing platelet smear correlated with TGF- $\beta 1$ because platelets contain a number of different growth factors, such as platelet-derived growth factor (PDGF), TGF- $\beta 1$ and TGF- $\beta 2$, and a hepatocyte growth factor (HGF) (30). In addition, the study in colorectal cancer found a positive correlation between TGF- $\beta 1$, CA19-9 and fucosyltransferase 3 and 6 leading to enhance cancer cell migration through upregulation of TGF$\beta$-mediated EMT (31). We suggest that there may be a relation between secretion of TGF- $\beta 1$ and CA19-9 in people with CCA which requires further investigation.

The challenge in the diagnosis of CCA requires a cooperative medical approach especially decisions and procedures regarding the effective tests to diagnose and screen for patients with CCA to reduce mortality rate. Currently, tumor biomarkers are perhaps the best option to diagnosis CCA patients who have not had ultrasonography. Many studies reported that CA19-9, CEA and CA-125 which are common tumor markers in CCA diagnosis lack specificity, sensitivity and can be found elevated in many cancers and other bile duct diseases (32). For these reasons, identification of novel markers with high sensitivity and specificity in serum are needed for surveillance and diagnosis of CCA. In this study, we found that the sensitivity of TGF- $\beta 1$ was $71.1 \%$ and the specificity was $68.9 \%$ at cutoff of $38.54 \mathrm{ng} / \mathrm{mL}$ which differentiated from CCA and normal groups. Moreover, TGF- $\beta 1$ distinguishes CCA from other diseases where sensitivity and specificity was $68 \%$ and $71 \%$, respectively. Many studies reported various levels of sensitivity and specificity of TGF- $\beta 1$, Khalifa $e t$ al. revealed $44 \%$ sensitivity, and $92 \%$ specificity of serum TGF- $\beta 1$ in discriminating between malignant and non-malignant cases in ovarian cancer. They suggested that TGF- $\beta 1$ is not useful as a marker for ovarian cancer because of its low sensitivity (33). Further supporting data that has been provided suggesting that plasma TGF- $\beta 1$ may be a useful serologic biomarker in detecting hepatocellular carcinoma 
early stage because it shows higher sensitivity (68\%) and specificity (95\%) at the cut-off level of $800 \mathrm{pg} / \mathrm{mL}$ (34). Generally, the cut-off value with higher sensitivity may be more useful for the purpose of screening if it has a sufficient range of specificity. Conversely, another cut-off with a higher specificity at the minimal expense of sensitivity is required in order to confirm the disease (35). Therefore, the cut-off TGF- $\beta 1$ level in this study can be a potential screening EMT-biomarker in CCA patients because it has the acceptable range of sensitivity for other cancer diagnosis.

We also combined TGF- $\beta 1$ with other laboratory biomarkers to determine whether in combination they provide diagnostic CCA tools. The combination of TGF- $\beta 1$ and ALP had improved effective diagnostic power in CCA diagnosis in terms of increasing sensitivity and specificity of $96 \%$ and $69 \%$, respectively. We found that values of diagnostic testing including PPV, NPV, accuracy, and LR of this combination were also acceptable; therefore, the use of TGF- $\beta 1$ and ALP can provide effective diagnosis of CCA. Univariate and multivariate of regression analyses was performed to investigate about clinicopathological variables were potentially associated with TGF- $\beta 1$ levels. The analysis showed that age and increased platelet smear were strongly associated with TGF- $\beta 1$ level. The age and TGF- $\beta 1$ associations have been widely studied because members of the TGF- $\beta$ superfamily play a crucial role in chondrocyte differentiation and maintenance of healthy articular cartilage in aging and old cartilage appears to be less protected by TGF- $\beta$ and shows significant alterations in TGF- $\beta$ signaling pathways (36). Moreover, Zhang and coworker study showed the serum TGF- $\beta 1$ concentration was found to be significantly negatively correlated with age $(r=-0.335, P=0.000)$ which is similar to our results which also showed a negative correlation between age and TGF- $\beta 1$ (coefficient $=-0.175, \mathrm{P}=0.045$ ) (37). On the other hand, a significant positive correlation was found with increased platelet smear. This finding is consistent with many other studies showing that platelets produce large amounts of TGF- $\beta 1$ (38).

\section{Conclusions}

The results of the current study show that high expression of TGF- $\beta 1$ in CCA tissues is significantly correlated with CCA development and poorer prognosis of patients. Moreover, serum level of TGF- $\beta 1$ in CCA patients is associated with metastasis status. Therefore, TGF- $\beta 1$ can be used as a potential biomarker for diagnosis and prognosis of CCA.

\section{Acknowledgments}

We appreciated to Dr. Malinee Thanee for laboratory guidance. We would like to acknowledge Prof. Ross $\mathrm{H}$ Andrews for editing the MS via Publication Clinic KKU, Thailand.

Funding: This work was supported by the grant from Khon Kaen University to A Techasen [600702]; Thailand Research Fund and Khon Kaen University to A Techasen (TRG5880023); the Higher Education Research Promotion and National Research University Project of Thailand, Office of the Higher Education Commission, through the Center of Excellence in Specific Health Problems in Greater Mekong Sub-region cluster (SHeP-GMS), Khon Kaen University (NRU582015).

\section{Footnote}

Conflicts of Interest: All authors have completed the ICMJE uniform disclosure form (available at http://dx.doi. org/10.21037/jgo.2019.01.03). The authors have no conflicts of interest to declare.

Ethical Statement: The authors are accountable for all aspects of the work in ensuring that questions related to the accuracy or integrity of any part of the work are appropriately investigated and resolved. This study was approved by the Human Ethics Committee of Khon Kaen University, based on the ethics of human specimen experimentation of the National Research Council of Thailand (HE571283 and HE531320). All participants signed an informed consent form before surgery.

Open Access Statement: This is an Open Access article distributed in accordance with the Creative Commons Attribution-NonCommercial-NoDerivs 4.0 International License (CC BY-NC-ND 4.0), which permits the noncommercial replication and distribution of the article with the strict proviso that no changes or edits are made and the original work is properly cited (including links to both the formal publication through the relevant DOI and the license). See: https://creativecommons.org/licenses/by-nc-nd/4.0/.

\section{References}

1. Sripa B, Kaewkes S, Sithithaworn P, et al. Liver fluke 
induces cholangiocarcinoma. PLoS Med 2007;4:e201.

2. Intajarurnsan S, Khuntikeo N, Chamadol N, et al. Factors Associated with Periductal Fibrosis Diagnosed by Ultrasonography Screening among a High Risk Population for Cholangiocarcinoma in Northeast Thailand. Asian Pac J Cancer Prev 2016;17:4131-6.

3. Treeprasertsuk S, Poovorawan K, Soonthornworasiri N, et al. A significant cancer burden and high mortality of intrahepatic cholangiocarcinoma in Thailand: a nationwide database study. BMC Gastroenterol 2017;17:3.

4. Bergquist A, von Seth E. Epidemiology of cholangiocarcinoma. Best Pract Res Clin Gastroenterol 2015;29:221-32.

5. Thiery JP, Acloque H, Huang RY, et al. Epithelialmesenchymal transitions in development and disease. Cell 2009;139:871-90.

6. Nieto MA, Huang RY, Jackson RA, et al. Emt: 2016. Cell 2016;166:21-45.

7. Pan JJ, Yang MH. The role of epithelial-mesenchymal transition in pancreatic cancer. J Gastrointest Oncol 2011;2:151-6.

8. Gumbiner BM. Cell adhesion: the molecular basis of tissue architecture and morphogenesis. Cell 1996;84:345-57.

9. Gamallo C, Palacios J, Suarez A, et al. Correlation of E-cadherin expression with differentiation grade and histological type in breast carcinoma. Am J Pathol 1993;142:987-93.

10. Li Z, Yin S, Zhang L, et al. Prognostic value of reduced E-cadherin expression in breast cancer: a meta-analysis. Oncotarget 2017;8:16445-55.

11. Jonsson MV, Salomonsson S, Oijordsbakken G, et al. Elevated serum levels of soluble E-cadherin in patients with primary Sjogren's syndrome. Scand J Immunol 2005;62:552-9.

12. Matsuzaki K, Date M, Furukawa F, et al. Autocrine stimulatory mechanism by transforming growth factor beta in human hepatocellular carcinoma. Cancer Res 2000;60:1394-402.

13. Chen Y, Ma L, He Q, et al. TGF-beta1 expression is associated with invasion and metastasis of intrahepatic cholangiocarcinoma. Biol Res 2015;48:26.

14. Duangkumpha K, Techasen A, Loilome W, et al. BMP7 blocks the effects of TGF-beta-induced EMT in cholangiocarcinoma. Tumour Biol 2014;35:9667-76.

15. Tacke F, Gabele E, Bataille F, et al. Bone morphogenetic protein 7 is elevated in patients with chronic liver disease and exerts fibrogenic effects on human hepatic stellate cells. Dig Dis Sci 2007;52:3404-15.
16. Weiskirchen R, Meurer SK, Gressner OA, et al. BMP-7 as antagonist of organ fibrosis. Front Biosci (Landmark Ed) 2009; 14:4992-5012.

17. Ma H, Lu Y, Marchbanks PA, et al. Quantitative measures of estrogen receptor expression in relation to breast cancer-specific mortality risk among white women and black women. Breast Cancer Res 2013;15:R90.

18. Lazar D, Taban S, Ardeleanu C, et al. The immunohistochemical expression of E-cadherin in gastric cancer; correlations with clinicopathological factors and patients' survival. Rom J Morphol Embryol 2008;49:459-67.

19. Zhou YN, Xu CP, Han B, et al. Expression of E-cadherin and beta-catenin in gastric carcinoma and its correlation with the clinicopathological features and patient survival. World J Gastroenterol 2002;8:987-93.

20. Ashida K, Terada T, Kitamura Y, et al. Expression of E-cadherin, alpha-catenin, beta-catenin, and CD44 (standard and variant isoforms) in human cholangiocarcinoma: an immunohistochemical study. Hepatology 1998;27:974-82.

21. Techasen A, Loilome W, Namwat N, et al. Loss of E-cadherin promotes migration and invasion of cholangiocarcinoma cells and serves as a potential marker of metastasis. Tumour Biol 2014;35:8645-52.

22. Aoki M, Ishigami S, Uenosono Y, et al. Expression of BMP-7 in human gastric cancer and its clinical significance. Br J Cancer 2011;104:714-8.

23. Elahi M, Rakhshan V, Ghasemian NT, et al. Prognostic value of transforming growth factor beta 1 [TGF-beta1] and matrix metalloproteinase 9 [MMP-9] in oral squamous cell carcinoma. Biomarkers 2012;17:21-7.

24. Wendt MK, Allington TM, Schiemann WP. Mechanisms of the epithelial-mesenchymal transition by TGF-beta. Future Oncol 2009;5:1145-68.

25. Miyazono K. Transforming growth factor- $\beta$ signaling in epithelial-mesenchymal transition and progression of cancer. Proc Jpn Acad Ser B Phys Biol Sci 2009;85:314-23.

26. Araki K, Shimura T, Suzuki H, et al. E/N-cadherin switch mediates cancer progression via TGF-beta-induced epithelial-to-mesenchymal transition in extrahepatic cholangiocarcinoma. Br J Cancer 2011;105:1885-93.

27. Sato Y, Harada K, Itatsu K, et al. Epithelial-mesenchymal transition induced by transforming growth factor\{beta\}1/Snail activation aggravates invasive growth of cholangiocarcinoma. Am J Pathol 2010;177:141-52.

28. Saito H, Tsujitani S, Oka S, et al. An elevated serum level of transforming growth factor-beta 1 (TGF-beta 1) significantly correlated with lymph node metastasis 
and poor prognosis in patients with gastric carcinoma. Anticancer Res 2000;20:4489-93.

29. Li X, Yue ZC, Zhang YY, et al. Elevated serum level and gene polymorphisms of TGF-beta1 in gastric cancer. J Clin Lab Anal 2008;22:164-71.

30. Weibrich G, Kleis WK, Hafner G, et al. Growth factor levels in platelet-rich plasma and correlations with donor age, sex, and platelet count. J Craniomaxillofac Surg 2002;30:97-102.

31. Hirakawa M, Takimoto R, Tamura F, et al. Fucosylated TGF-beta receptors transduces a signal for epithelialmesenchymal transition in colorectal cancer cells. Br J Cancer 2014;110:156-63.

32. Alvaro D. Serum and bile biomarkers for cholangiocarcinoma. Curr Opin Gastroenterol 2009;25:279-84.

33. Khalifa A, Kassim SK, Ahmed MI, et al. Transforming growth factor-beta and nitrates in epithelial ovarian cancer.

Cite this article as: Kimawaha $\mathrm{P}$, Jusakul A, Junsawang $\mathrm{P}$, Loilome W, Khuntikeo N, Techasen A. Circulating TGF- $\beta 1$ as the potential epithelial mesenchymal transition-biomarker for diagnosis of cholangiocarcinoma. J Gastrointest Oncol 2020;11(2):304-318. doi: 10.21037/jgo.2019.01.03
Dis Markers 1999;15:249-58.

34. Song BC, Chung YH, Kim JA, et al. Transforming growth factor-beta 1 as a useful serologic marker of small hepatocellular carcinoma. Cancer 2002;94:175-80.

35. Griner PF, Mayewski RJ, Mushlin AI, et al. Selection and interpretation of diagnostic tests and procedures. Principles and applications. Ann Intern Med 1981;94:557-92.

36. van der Kraan PM. Age-related alterations in TGF beta signaling as a causal factor of cartilage degeneration in osteoarthritis. Biomed Mater Eng 2014;24:75-80.

37. Zhang N, Wu XY, Wu XP, et al. Relationship between age-related serum concentrations of TGF-beta1 and TGFbeta 2 and those of osteoprotegerin and leptin in native Chinese women. Clin Chim Acta 2009;403:63-9.

38. Thiele J, Kvasnicka HM. Grade of bone marrow fibrosis is associated with relevant hematological findings-a clinicopathological study on 865 patients with chronic idiopathic myelofibrosis. Ann Hematol 2006;85:226-32. 